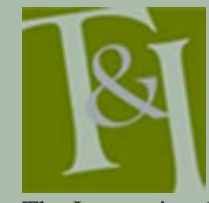

The International Journal for Translation \& Interpreting Research trans-int.org

\title{
Hybrid modelling of intelligence and linguistic factors as predictors of translation quality
}

\section{Reza Pishghadam}

Ferdowsi University of Mashhad, Iran

pishghadam@um.ac.ir

\section{Shaghayegh Shayesteh}

Ferdowsi University of Mashhad, Iran

shaghayegh.shayesteh@gmail.com

\section{Fatemeh Heidari}

Ferdowsi University of Mashhad, Iran

fatimamashhad@yahoo.com

DOI: 10.12807/ti.108201.2016.a07

\begin{abstract}
That translators should possess a comprehensive knowledge of the source and target language has long been considered a fundamental prerequisite within translation studies. However, this field seems to overlook the strategic applications of other related areas. Accordingly, the current study particularly sought to adopt an interdisciplinary approach and investigate the quality of forward and backward translation performance based on a pair of complementary viewpoints. From the intelligence-based view, the likely influence of Narrative Intelligence (NI) alongside Verbal Intelligence (VI) was examined. From the linguistic-based view, the L1 and L2 proficiency levels of translators were taken into consideration in order to ultimately determine whether NI, VI or L1/L2 proficiency can predict improved quality of translated texts in both directions. The research involved participation by 231 university students who were selected to complete a set of scales and tests. Structural Equation Modelling (SEM) was utilized to evaluate the correlation between the targeted variables. Upon analysing the data it was found that NI, VI, and L1/L2 proficiency correlate significantly - although differently - with the quality of the translated texts. The results are discussed, and some of their implications are identified and considered in the context of translation studies.
\end{abstract}

Keywords: narrative intelligence, verbal intelligence, translation, SEM, language proficiency

\section{Introduction}

In order to adopt a polyvalent approach to scientific research, we basically need to go beyond the scope of a single discipline. Multidisciplinary or interdisciplinary research has thus been developed from the need to integrate individual contributions from different disciplines to yield innovative avenues to expedite scientific discovery and focus on the solution to long-standing questions. In line with this movement, it appears that translation studies has attempted to embed ideas from various fields such as sociology (e.g., Sechrest, Fay, \& Zaidi, 1972), philosophy (e.g., Benjamin, 1989), and psychology (e.g., Giuseppe, 1981), in order to obtain further findings. From amongst the 
mentioned realms, psychology enjoys an increased momentum due to its involvement with attitude and mentality (Giuseppe, 1981). To be specific, the psychological aspect of translation is pertinent to those areas in which it deals with mental and cognitive processes during the translation process to generate an intelligible translated text (Campbell, 2000).

From this perspective, Wills (1998) views translation as a psycholinguistic formulation process by which the message of the source language is reproduced in the target language. Moreover, Albir and Alvers (2009, p. 54) believe that translation is "the result of cognitive processing carried out by translators". Meanwhile, one of the prominent factors of such cognitive processes is 'intelligence' (Goleman, 1995; Pishghadam, 2007, 2009; Zavalaa, 2012), which may play a substantial role in the conduct of learning and doing tasks such as translation. Due to its significance, a body of research has been devoted to probing the role of different types of intelligence in translation (e.g., Shangarffam \& Abolsaba, 2009; Zavalaa, 2012); however, the likely impact of Narrative Intelligence (NI) on translation has still remained unidentified.

In recent past, the young concept of NI has attracted growing attention in a variety of disciplines such as psychology, sociology, literature, etc. (Randall, 1999). In a general sense, NI is referred to as "the capacity both to formulate (compose, narrate) and to follow (understand, read) the story of our own life" (Randall, 1999, p. 13). In essence, NI is looked upon as a mode of communication, which specifically deals with inter- and intra-personal competencies tied with Verbal Intelligence (VI) (Randall, 1999). In correspondence with NI, the application of VI as another effective type of intelligence in the use and comprehension of language is not clear enough within translation studies. In retrospect, given that a translator is a 'special category of a communicator' (Hatim \& Mason, 1997), it is expected that NI and VI, owing to their underlying nature, may probably influence the translation ability and quality.

In addition to all the stated points, translators and scholars mutually agree that efficient translators, in the first place, should have an exhaustive knowledge of the source and target language (Birjandi \& Farahzad, 2010). Therefore, linguistic factors including both L1 and L2 vocabulary, grammar, and overall language proficiency are deemed fundamentally essential. Taken together, it is hypothesized that investigating traditionally valued linguistic factors, mingled with the contemporary notion of VI and specifically NI, may yield a more realistic image of the translation mechanism. Hence, in the current study, we propose to adopt a pair of complementary viewpoints. From the intelligence-based view, we delve into and compare the probable association between NI, VI, and the quality of translation in both directions (i.e., L2-L1 and L1-L2), and offer productive applications within translation studies. From the linguistic-based view, we equally take the L1 and L2 proficiency levels of the translators into account, and eventually conclude whether NI, VI, or L1/L2 linguistic proficiency correlate differently with the ability and quality of forward (L1-L2) or backward translation (L2-L1) performance.

\section{Theoretical Background}

In this section we examine the theoretical frameworks of intelligence and language proficiency in greater detail. 


\subsection{Intelligence-based View}

Since the introduction of the unitary hypothesis of mental intelligence by Binet (1905), a number of proposals have been made to illuminate the structure and nature of intelligence. For instance, to enumerate the major ones, Gardner (1990) in his Multiple Intelligences (MI) theory indicated that intelligence is not a single construct; rather, it consists of eight different types including VI. Years later, Goleman (1995) posited emotional intelligence as a further type. And later still, Bruner (1996) suggested NI as an additional type of intelligence.

2.1.1 Narrative Intelligence. It is assumed that narratives aid human beings to make sense of the world around them (Booth, 1988; Bruner, 1987; Randall, 1999). Indeed, Bruner (1991) posits that narrative is a fundamental way of meaning making for the purpose of communication. Therefore, according to Bruner (1991, p. 6), the basic concern is not how the narratives are constructed, but rather how they function as "an instrument of mind in the construction of reality". Technically speaking, this human flair for turning experience into narrative form is called NI (Mateas, 1999). As Randall (1999) expressed it, NI is the ability to produce and understand narratives which can enable individuals to make sense of a situation, an event, or an emotion. Randall (1999, p. 15) proposes that NI consists of intertwining sub-capacities which he identifies as the ability to "emplot, characterize, narrate, genreate, and thematize" using terms borrowed from storytelling, movies, and other related genres (Pishghadam, Baghaei, Shams, \& Shamsaee, 2011).

1- Emplotment: Editing, summarizing, and prioritizing the whole events of a story to fulfil the present aim of a narrator and create a plot which is the fundamental element of each story.

2- Characterization: Characterizing 'a working picture' of both ourselves and others on the basis of existing and emerging cues and clues.

3- Narration: As the heart of NI, determines the level of communication we sustain with others by conveying the meaning of the story through drawing logical linkage between events, causes, and consequences.

4- Genre-ation: Organizing a chain of events into predictable patterns to make sense of a human happening. In particular, each narrative consists of specific events that are constituents of a broader type or genre.

5- Thematization: Recognizing the main ideas of the story from recurring happenings and patterns of meaning that are observed within a single situation (Randall, 1999).

Given the inherent interdisciplinarity of the concept, NI has been applied to a number of different fields. Traditionally it was merely used in art and literature classes, but within a brief space of time other fields such as mathematics and sciences similarly attempted to embrace NI as a knowledge construction tool (deFreitas, 2008). With regards to language and education, NI was initially employed in the field of linguistics to identify the factors which affect language learning procedure (Labov, 1997). Later on, it was utilized to discover how learners experience learning a language (Pishghadam \& Motakef, 2012; Pishghadam \& Shams, 2013). However, in the realm of translation studies (TS), although narrative approaches have been investigated to throw further light on the translation of literary texts (Baldo, 2011), there is scant research concerning the role of NI in translation generally.

2.1.2 Verbal Intelligence. Building upon its existence in major hierarchical models of human intelligence (e.g. Binet, 1905; Gardner, 1990), VI is broadly considered a substantial attribute. VI, as one of the manifold types of Gardner's (1990) MI paradigm, is the enhanced ability to have an in-depth 
understanding of the use, rhythm, and meaning of words, which manifests in both written and spoken language. While every individual is born with a measure of this type of intelligence, some seem more gifted in this area. Specifically, individuals with a higher degree of verbal IQ potential enjoy broad access to vocabularies, which may enable them to better persuade others. VI is typically regarded as the most widely shared intelligence due to its critical role in helping people to connect and communicate, and thereby enhance their interpersonal relationships (Gardner, 1990). Although numerous studies of this type of cognitive competence have been carried out in different domains, including language education (e.g., Mohammadi \& Mousalou, 2012; Pishghadam et al., 2011), translation studies remains largely unacquainted with it. Nevertheless, it is hypothesized that translators strongly need full command of this intellectual attribute in order to reproduce the language of the source text into a sophisticated, assimilable form in the target one.

\subsection{Linguistic-based View}

Notwithstanding the recent scholarly focus on cognitive ability (e.g. Malakoff, 1992), translation has long been treated as a matter of linguistic excellence (Campbell, 1998). Since translation can be considered as a branch of applied linguistics, its emphasis on language proficiency is naturally inevitable (AlShareef, 2011).

2.2.1 Language Proficiency. Translation practice demands a unique set of competences, which definitely includes the repertoire of source and target languages (Neubert, 2000). Throughout the process of translating, translators should pay heed to all linguistic properties such as grammar, vocabulary, syntax, and register (Uzawa, 1996). That is to say, high levels of proficiency in L2 contribute to improved ability in application of stylistic varieties (Campbell, 1998). As Campbell (1998) repeatedly remarks, linguistic competence is the most rudimentary element of translation. In order to create an authentic, faithful text, in the first place translators need to become proficient in the grammar of the target language at the sentence level and subsequently at the textual level (Campbell, 1998). Accordingly, a plethora of research has explicitly explored the influence of L2 proficiency on translation skill. It is a commonly held view that translation from the less proficient language to the more proficient one is almost always faster and more accurate in comparison to the reverse direction (Francis \& Gallard, 2005; Kroll \& Stewart, 1994; Potter et al., 1984). While some scholars (De Groot \& Hoeks, 1995; Kroll \& Curley, 1988) indicate that the L1 translation performance of bilinguals with different levels of L2 proficiency may differ significantly, others (Potter et al., 1984) report a neutral role of this variable.

On the whole, as Snodgrass (1993) criticized, relatively little empirical evidence exists concerning the performance of the translation task. Over 20 years later, there has not yet been a noticeable shift in this respect. Translation has only been narrowly investigated within the psycholinguistic field (Bordag \& Pechmann, 2008). Although language studies are replete with such new methods and paradigms, only a small number of studies have focused on translation from this perspective (Bordag \& Pechmann, 2008). Therefore, in this study, we seek to trace translators' mental constructs and juxtapose cognitive and linguistic abilities to deduce whether the NI, VI, or linguistic proficiency of bilingual translators better correlate with the quality of their translated texts in both directions. In sum, the current study attempts to respond to the following questions: 
1. Does NI have any influence on the quality of forward or backward translation?

2. Does VI have any influence on the quality of forward or backward translation?

3. Does the quality of translation performance differ between translators with various L1 and L2 proficiency levels?

\section{Methodology}

\subsection{Participants}

For the purpose of this study, a cohort of 231 Iranian university students (Male=101, Female=130) were convenience selected based on their willingness to participate. Ethical approval was primarily obtained from the participants prior to the data collection procedure. The students were also informed that their answers would be kept absolutely confidential and used for the purpose of research only. They were all senior students of translation studies from four accredited universities (selected annually by the Ministry of Science, Research, and Technology) in Mashhad and Tehran, in Iran, who had already passed several courses on translation-in-practice. Their ages varied between 18 and 37 (Mean=21.8), and they were bilinguals who spoke Persian and English as their first and foreign language, respectively.

\subsection{Instruments}

In order to fulfil the objectives of the study in hand, multiple scales encompassing the Narrative Intelligence Scale (NIS), Wechsler's Adult Intelligence Scale (WAIS- III) and Translation Quality Assessments Scale (TQAS), together with different English and Persian proficiency tests were employed.

3.2.1 NI. To measure the sample participants' degree of NI, the NIS as constructed and validated by Pishghadam et al. (2011) was utilized. The scale includes 35 items with a scoring scheme of 1 to 5 , producing a score range of 35 to 175 . Its content validity was established by means of designing the scale grounded in Randall's (1999) NI framework. In addition, its construct validity was ratified through Rasch rating scale model (RSM) (Andrich, 1987) yielding an item and person reliability of .99 and .98 respectively. The overall reliability of the scale in this study, measured via Cronbach alpha, was .98.

To examine narrative performance, two pertinent tasks were set:

Task 1. As a narrative reconstruction task, the participants were given a picture story (see Appendix) to look at for one minute, and subsequently asked to tell the story in Persian.

Task 2. As a personal narrative task, the participants were asked to tell a memorable story of their first day of the Iranian/Persian New Year based on the prompt 'Please tell the story of your first day of New Year'. The logic behind choosing this task was that there existed a greater likelihood of recall given the proximity to the time of the interview (almost a month). Moreover, New Year is the most common calendar event that is almost equally observed by all Iranians. Also, because participants generally share identical conventions in terms of their first day of the New Year, what to say was roughly predictable and what remained was merely how to tell the story.

3.2.2 VI. To evaluate the verbal intellectual functioning of the participants, the most frequently used test of WAIS-III (1981) was administered. The Persian version of the WAIS Vocabulary subsection employed in the current study is 
composed of 40 words. The translated version was specifically provided by the Azmoon Padid Institute (1993) in Tehran, Iran. The reliability coefficient for Verbal IQ is .97. Also, the estimated correlation between this vocabulary subtest and the WAIS-III verbal scale is high $(\mathrm{r}=.91-.95)$. To substantiate the concurrent validity of WAIS-III, its correlation with other valid intelligence scales was taken into account. For instance, its calculated correlations with Standford-Binet Intelligence Scale Fourth Edition (SB-IV) composite scores were all high ( $\mathrm{r}=.78$ to .89) (Silva, 2008). The Cronbach alpha for the vocabulary subsection in this study was .94 .

3.2.3 English Vocabulary and Grammar. In order to evaluate the participants' mastery of English grammar, the structure module of TOEFL PBT published by ETS (2005) was utilized. Given that the validity of this scale had already been confirmed, it was used in the present study. This scale consists of 40 items, 15 of which display a sentence with a blank. The 25 following items include sentences with four underlined words or phrases. The participants were required to identify and mark the wrong parts on the answer sheets. The Alpha Cronbach estimated for the current instrument in this study was 89 .

To assess the participants' knowledge of vocabulary, the Word Associates Test (Read, 1993) was administered. The test includes 40 items. Each single item is a combination of a stimulus word (adjectives) along with eight choices located separately in two boxes: the first (AD) and the second four choices (E-H). Among the choices located in the left box, one to three words could be the synonyms of the stimulus, whereas among the ones located in the right box, one to three co-occurring words could collocate with the stimulus. The test was found to be valid by correlating it to a test of L2 reading ability ( $\mathrm{r}=.88)$ and its reliability was .91 (Qian, 1999). The Alpha Cronbach for the current instrument in this study was .93.

3.2.4 Persian Vocabulary and Grammar. To measure the Persian vocabulary knowledge of the participants, a Persian vocabulary test was designed and validated. Based on the items employed in Iran's National Entrance Examination (INEE) and in consultation with experts in the field of language measurement, a Persian vocabulary test was constructed. The test comprised 20 items in a multiple-choice form. To substantiate the construct validity of the Persian vocabulary test, we applied Rasch measurement employing WINSTEPS software (Linacre, 2009). The overall analysis of the items resulted in an item separation index of 6.12 with an item reliability of .94 , and a person separation index of 4.29 with a person reliability of .90 .

Compatible with the Persian vocabulary knowledge, a Persian grammar test was utilized to measure the grammar knowledge of the participants. The test comprised 20 items in multiple-choice format, all measuring the grammar knowledge of the learners. To substantiate the construct validity of the test, Rasch measurement was again used. The results revealed that except for item 3 , which was misfitting, all other items were uni-dimensional, with an item separation index of 5.4 and an item reliability of .91 , and a person separation index of 5.11 with a person reliability of .87 .

3.2.5 Translation Quality. One English text along with one Persian text was used to evaluate the participants' translation performance quality in L2-L1 and L1-L2 directions. Each text was composed of 250 words on an everyday life theme with which the students were typically acquainted. To assess the quality of their translated texts, Waddington's (2001) model of translation assessment, 
method C, was exercised. Waddington (2001) believes that method C is a holistic method of assessment which evaluates translation competence as a unitary concept; it requires the raters to account three distinct aspects of the participant's performance (i.e., accuracy of transfer of source language content, quality of expression in target language, and degree of task completion). The rationale behind choosing this model was that, relying on its holistic nature, assessment is performed more quickly.

\subsection{Procedure}

3.3.1 Data Collection. The data collection process was completed in approximately four months (September-December 2013) and performed in three separate sessions.

- Session one: The researchers of this study met each volunteer student individually and listened to, recorded, and later transcribed their narratives. These narratives were then rated by two raters who were NI experts, using NIS with the estimated inter-rater reliability .91.

- Session two: After a week, the participants were asked to answer the tests on Persian and English vocabulary and grammar, during a period of one hour and a half. Their reliability coefficients were reported in the previous section.

- Session three: A week later, the participants were asked to complete the Persian version of WAIS-III. This step was likewise rated by a pair of raters, holding an estimated inter-rater reliability of .96. Finally, with regards to translation quality, the participants who were familiar with the procedure were asked to translate a pair of texts (taken from the reading section of TOEFL), one from English into Persian and the other from Persian into English during one hour and a half. Their translated texts were similarly rated by two experts in translation (university lecturers teaching TS) based on Waddington's (2001) model of translation assessment, method C. The inter-rater reliability was calculated as .91 .

3.3.2 Data Analysis. The gathered data was entered into SPSS 20 and AMOS 18 software to be analysed through Structural Equation Modeling (SEM), which is a general statistical modelling technique utilized to study the relationships among a number of variables in a matrix form. This multivariate approach is designed to verify a theoretical or conceptual model whose major focus is on abstract psychological variables (Byrne, 2001). Multiple exclusive features make SEM different from other measuring tools: First, SEM is in essence confirmatory rather than exploratory. Second, contrary to conventional multivariate procedures, SEM maintains estimates of error variance parameters. Third, besides the observed variables, SEM equally takes the latent variables into account (Byrne, 2001).

In the first place, the internal reliability together with descriptive statistics and correlations of the intended variables was obtained. Thereafter, employing SEM, two identical models were extracted with regards to forward and reverse translation skills. Their parameter estimates and fit indices were subsequently calculated. Specifically, while fit indices are estimated to see how well the model fits the data, parameter estimation indicates the relationships between the variables (Byrne, 2001). 


\section{Results}

\subsection{Descriptive Statistics}

As Table 1 clearly depicts, while some of the variables including NI ( $\mathrm{r}=$ $.61, \mathrm{p}<.01)$ and Persian vocabulary $(\mathrm{r}=.43, \mathrm{p}<.01)$ correlated slightly higher with forward translation, others including VI $(\mathrm{r}=.33, \mathrm{p}<.01)$, English grammar $(\mathrm{r}=.22, \mathrm{p}<.05)$, and English vocabulary $(\mathrm{r}=.46, \mathrm{p}<.01)$ correlated relatively higher with backward translation. Also, as it is shown, Persian grammar has not been correlated significantly with either direction. In order to have a more extensive understanding of the different roles of NI, VI, and L1/L2 proficiency in both forward and backward translation directions, SEM was employed.

Table 1. Descriptive statistics and correlations

\begin{tabular}{|c|c|c|c|c|c|c|c|c|c|}
\hline & Mean (SD) & 1 & 2 & 3 & 4 & 5 & 6 & 7 & 8 \\
\hline 1. $\mathrm{NI}$ & $68.2(5.7)$ & 1.00 & & & & & & & \\
\hline 2. VI & $58.3(4.8)$ & $.49^{\star \star}$ & 1.00 & & & & & & \\
\hline 3. GramP & $21.60(2.35)$ & .11 & .11 & 1.00 & & & & & \\
\hline 4. VocP & $38.42(3.73)$ & $.21^{*}$ & .17 & .09 & 1.00 & & & & \\
\hline 5. GramE & $33.62(3.41)$ & .15 & .10 & .11 & .08 & 1.00 & & & \\
\hline 6. VocE & $320.14(10.31)$ & $.31^{\star *}$ & .15 & .07 & $.21^{\star}$ & $.32^{\star *}$ & 1.00 & & \\
\hline 7. FTrasnlation & $6.45(1.18)$ & $.61^{\star \star}$ & $.22^{\star}$ & .10 & $.43^{\star \star}$ & $.21^{*}$ & $.41^{* *}$ & 1.00 & \\
\hline 8. BTranslation & $4.02(1.12)$ & $.58^{\star \star}$ & $.33^{\star *}$ & .19 & $.38^{\star *}$ & $.22^{\star}$ & $.46^{\star *}$ & $.68^{\star *}$ & 1.00 \\
\hline
\end{tabular}

\subsection{SEM Parameter Estimates}

Two similar models were identified for analysis in this study. Model 1 (Figure 1 below) depicts the extent to which NI, VI, and L1/L2 proficiency, in addition to their sub-constructs, are predictors of forward translation.

The path numbers present standardized values of the model parameters (correlation and regression coefficients). The numbers marked above the arrows show the amount of variation explained by the paths leading to it. According to the model, while only $15 \%$ of the variation in forward translation is accounted for by VI, the explained variances of NI (46\%), L1 (43\%), and L2 proficiency (49\%) are somewhat close. Therefore, the researchers' assumption is that, regardless of VI, both cognitive and linguistic factors significantly explain an acceptable degree of the variation within forward translation. Moreover, as the model further shows, the latent variables, L1 and L2 proficiency, develop out of two other latent variables, namely grammar and vocabulary. However, the variance in both L1 and L2 proficiency is mainly accounted for by lexical $(\mathrm{L} 1=81 \%, \mathrm{~L} 2=72 \%)$ rather than grammatical skill. Moreover, among the observed scores for the five sub-abilities of NI, the 'Genere-ation' scores show the highest variance (91\%) explained by the latent variable 'NI' in forward translation; this variable can also explain 'Thematization' (88\%), 'Emplotment' (83\%), ‘Characterization' (82\%), and 'Narration' (73\%) to varying degrees.

Model 2 manifests the extent to which NI, VI, and L1/L2 proficiency, alongside with their sub-constructs, are predictors of backward translation. 


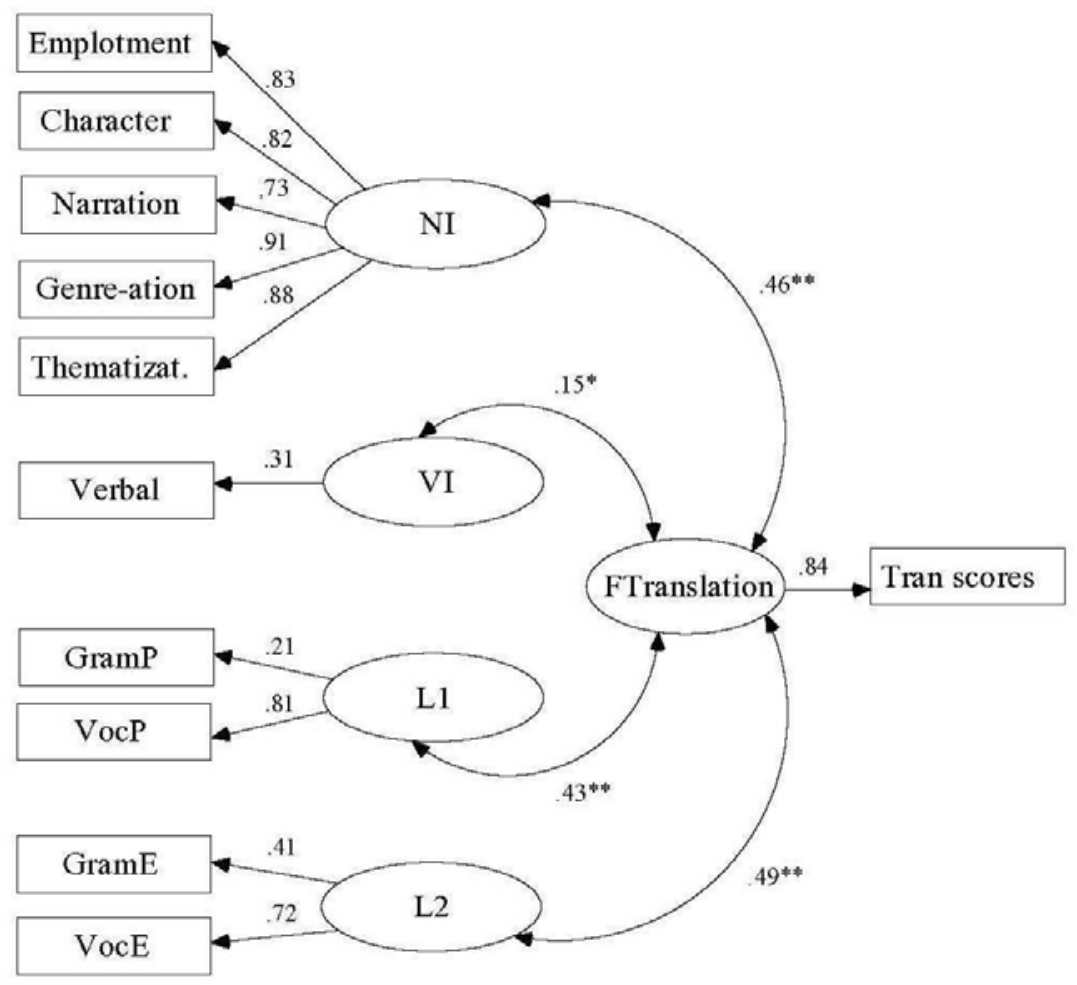

Figure 1. Narrative intelligence (NI), verbal intelligence (VI), first language (L1), and second language (L2) as predictors of translation, ${ }^{*} \mathrm{p}<.05$. ${ }^{* *} \mathrm{p}<.01$

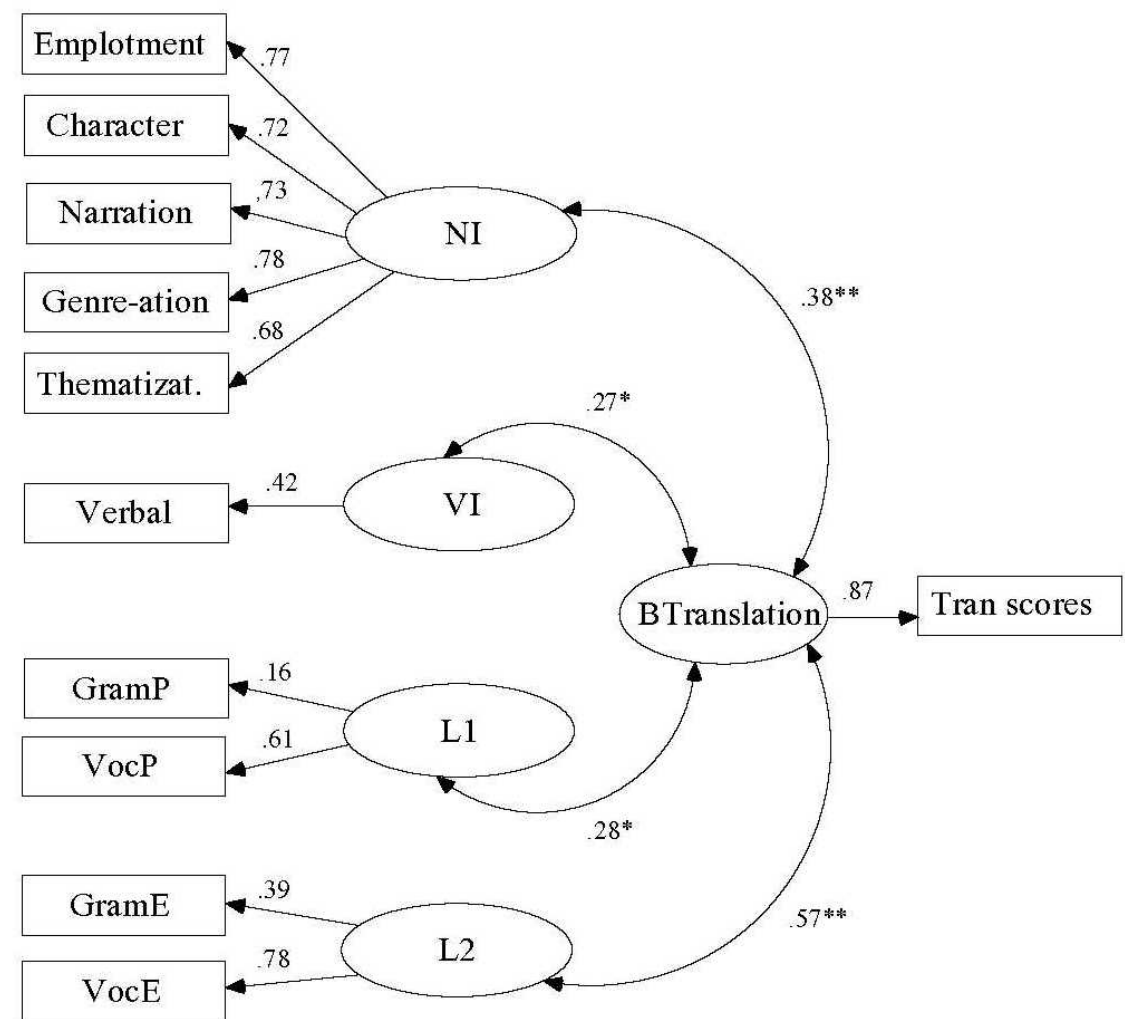

Figure 2. Narrative intelligence (NI), verbal intelligence (VI), first language (L1), and second language (L2) as predictors of backward translation, ${ }^{*} \mathrm{p}<.05$. ${ }^{* *} \mathrm{p}<.01$ 
In correspondence with model 1 , model 2 indicates the amount of backward translation variations explained by NI, VI, L1, and L2 proficiency. Based on the model, L2 proficiency accounts for the highest variation (57\%) in backward translation. Afterwards, NI is ranked the second with $37 \%$ of explained variation, and ultimately $28 \%$ and $27 \%$ of the variation is explained by L1 proficiency and VI, respectively. To conclude, in comparison with cognitive factors, the role of linguistic factors is seemingly more influential in the backward (L1 to L2) direction. Similarly to forward translation, the amount of backward translation variation explained by L1 and L2 proficiency is better accounted for by lexical ( $\mathrm{L} 1=61 \%, \mathrm{~L} 2=78 \%$ ) rather than grammatical skill. In addition, from amongst the five sub-constructs of NI, 'Genre-ation' yields the highest variance (78\%) explained by this latent variable. This variable can also explain 'Emplotment' (77\%), 'Narration' (73\%), 'Characterization' (72\%), and 'Thematization' (68\%) to varying degrees.

\subsection{SEM Fit Indices}

The fitting indices concerning forward and backward translation are presented in Table 2.

Table 2. Goodness of fit indices

\begin{tabular}{lccccccc}
\hline & $X^{2}$ & df & $X^{2} / d f$ & GFI & TLI & CFI & RMSEA \\
\hline Acceptable Range & & & $<3$ & & $>90$ & & $<.08$ \\
FTranslation & 9.29 & 3 & 2.67 & .96 & .93 & .95 & .06 \\
BTranslation & 10.61 & 3 & 2.65 & .93 & .90 & .94 & .07 \\
\hline
\end{tabular}

The goodness of fit indices utilized in this study are: $\chi^{2} / \mathrm{df}$ (Chi-square divided by the degrees of freedom), AGFI (Adjusted Goodness of Fit Index), IFI (Incremental Fit Index), TLI (the Tucker -Lewis Index), CFI (Comparative Fit Index), and RMSEA (Root Mean Square Error of Approximation). An acceptable model is indicated by $\chi^{2} / \mathrm{df}<3$, AGFI $>90$, IFI $>90$, TLI $>90$, CFI $>90$, and RMSEA $<0.08$ (Kaplan 2009). As the table reveals, the indices lie wholly within the safe area.

\section{Discussion}

The main objectives of the current study were to probe the influence of the participants' linguistic and cognitive competences on their forward and backward translation quality. In particular, it was intended to verify whether NI, VI, or L1/L2 proficiency could predict the participants' translation performance.

With regards to the first intention of the study, the results showed that NI significantly impacts upon both translation directions. In its simplest sense, translation is the conversion of one linguistic system to another, which is a sort of narrative practice. One probable justification may centre on the underlying nature of narratives. In fact, narratives develop out of a lifetime of relevant experiences (Mateas, 1999). To cipher and decipher these experiences, context undoubtedly plays a persuasive role (Li et al., 2012). The extensively invoked notion of context is of parallel importance in translation studies, too (Baker, 2006). Translators are basically required to decontextualize the source text and re-contextualize it for the target text. Accordingly, it is indispensable for translators to translate every detail of the text in careful consideration of the social and cultural context to ensure the audience's complete involvement (Neubert, 2000). In essence, translation is a 
means of enabling communication and dialogue between different cultures. In turn, narratives are principal and inescapable modes of communication (Somers \& Gibson, 1994). Therefore, successful communications - and specifically on the part of translators, translations - require an acceptable amount of NI. It therefore seems logical to corroborate the association between NI and translation on the basis of their common background.

Yet, based on the results, in comparison with backward translation, the influence of NI on forward translation is relatively more significant. That is to say, translators with a somewhat higher NI level may produce a better-quality translated text in forward translation. This might imply that, because translators presumably face far more disparate experiences in their L1culture and context, a correspondingly greater degree of NI could be required to rebuild this complex reality in the target language. Moreover, upon inspecting the models it was discovered that almost all the sub-constructs of NI correlated strongly and fairly equally with the intended super-construct. This indicates that each of these interdependent sub-constructs bears similar weight in the reconstruction of reality. It must however be noted that, with a subtle difference, 'Genre-ation' stands higher than the other sub-constructs of NI for both directions. According to Randall (1999), genre-ation hinges on the organization of a chain of events and concepts. Therefore, it seems rational to flag this feature as the most salient entity in translation study. Creating a wellorganized text is the foundation of all translation practice. Inadequate attention by the translator to the sequence of features in the target text might distort the originally intended theme of the source text, which may ultimately lead to incomprehension and bewilderment of target text readers.

Regarding the second aim of the study, it was found that VI bears a rather mild relationship to translation performance in both directions. Simply put, given that verbal IQ potentially contributes to a broader access to linguistic features in general, and vocabulary items in particular (Gardner, 1990), it can be concluded that this competence may generally provide translators with additional linguistic choices which inevitably lead to an improved generated text. Based on Manfredi's (2008) viewpoint, the most evident problems which arise in the course of translation seem to be rooted in words or expressions. What is more and according to the findings, this probable association appears to be somewhat stronger in the case of backward translation. A possible explanation might be that, throughout the reverse translation process, translators have wider target-language vocabulary access within their L1, which may result in an enhanced verbal ability in that direction.

Regarding the third purpose of the study, it emerged that both L1 and L2 proficiency meaningfully influence the quality of translated text. As Francis, Tokowicz, and Kroll (2014) recently observed, an increment in L2 proficiency reciprocally augments translation accuracy in both directions. This finding is consistent with the body of research literature (De Groot \& Hoeks, 1995; Kroll \& Curley, 1988) showing that greater linguistic proficiency gives rise to better translation performance. Without profound knowledge of both L1 and L2, translators may not be able to generate an accurate translation at all (Neubert, 2000). Our results here suggest that for both translation directions, vocabulary level may prove better than grammatical skill, indicated by vocabulary's higher correlational estimates with translation command in both L1 and L2 proficiency. This notion to some extent contradicts Manfredi's (2008) view which prioritized the role of grammar over vocabulary. As an explanation, it may be ventured that in some settings the major issue is to seek the most appropriate word from amongst a list of miscellaneous items, irrespectively of translation direction (L1-L2 or L2-L1). In that case, more 
comprehensive vocabulary knowledge facilitates each translation route in corresponding ways: how words are apprehended in L2-L1 and retrieved in L1-L2. If so then the primary role hitherto assigned to grammar may ultimately be downgraded. Moreover, it needs to be clarified that in certain genres (e.g., Law) effective translation may rely heavily on a very sound knowledge of grammar and syntax.

Taken overall, the results of this study place emphasis on developing psycholinguistic literacy in translation studies. The findings lead us to the conclusion that translation appears to go well beyond simply being proficient in both working languages. It seems that there are differences in translation command which may not be due to linguistic competence in isolation. In truth, translators are best served if their complex mindsets are directed toward cognitive orientations alongside linguistic knowledge (Neubert, 2000). As the basic concern of the current study, we have explored shifting the focus less toward linguistic features and more toward the cognitive ability of translators in generating high-quality translated texts. Practically speaking, we assume that, apart from linguistic excellence, translator cognition needs to be cultivated with psycho-intellectual skills. For example, in academic and translator training programs, some relevant theoretical courses could be incorporated into the curricula to raise awareness of how cognitive leverage affects the quality of translated texts. In addition, and given that here NI displayed a rather high correlation with translation performance, this attribute could be of significant usefulness to interested organizations as a further criterion of translator recruitment.

Finally, dynamic differences in the performance of translators confirm that translation skill must take account of individual differences as well (Campbell, 1998). This study has sought to do so by projecting intelligence and cognitive modelling into the context of translation studies. It must of course be borne in mind that studies of this kind are not without limitations, and so universal generalization of the findings is not recommended. First, our sample participants were selected from universities of Mashhad and Tehran, who are not representative of the large population of language translators in general. Moreover, we merely investigated bilingual translators whose L1 was Persian. In future research it is highly recommended to replicate the study with participants of different mother tongues. Last but not least, this paper attempted to reconcile linguistic and cognitive viewpoints as the essential need of translation performance. Various other questions arise: how can translators raise their level of NI/VI to polish their translated texts? Are the roles of NI, VI, or linguistic proficiency identical in bilingual and multilingual translators? Does gender affect translators' intellectual potentiality? These and other conspicuous aspects remain to be probed in future studies.

\section{Acknowledgements}

We gratefully acknowledge that the foregoing study was supported by a grantin-aid of research from Ferdowsi University of Mashhad in 2014 (contract code: 30250), without which this research would not have been possible. 


\section{References}

Albir, A. H., \& Alvers, F. (2009). Translation as a cognitive activity. In Munday, J. (Ed.), Routledge companion to translation studies (pp. 54-73). London, England: Routledge.

Al-Shareef, K. (2011). Translation: Science, art, or skill? Unpublished article. Palestine Polytechnic University, Palestine.

Azmoon Padid Institute. (1993). The standardization of Wechsler's adult intelligence scale III. Tehran, Iran.

Andrich, D. (1978). A rating formulation for ordered response categories. Psychometrika, 43(4), 561-573.

Baldo, M. (2011). Narrative theory and translation/interpreting studies. Paper presented in the conference on research models in translation studies II, University of Manchester, UK.

Benjamin, A. (1989). Translation and the nature of philosophy. A new theory of words. London and New York: Routledge.

Binet, A. (1905). A propos la mesure de l'intelligence. L'Annee Psychol, 2, 411-465.

Birjandi, P., \& Farahzad, F. (2010). The ability to translate and foreign language proficiency. Perspectives: Studies in Translatology, 5(2), 191-199.

Booth, W. (1988). The company we keep: An ethics of fiction. Berkeley: University of California Press.

Bordag, D., \& Pechmann, T. (2008). Grammatical gender in translation. Second Language Research, 42(2), 139-166.

Bruner, J. (1987). Life as narrative. Social Research, 54, 11-32.

Bruner, J. (1996). The culture of education. Cambridge, MA: Harvard University Press.

Byrne, B. M. (2001). Structural equation modeling with AMOS: Basic concepts, applications, and programming. New Jersey: Lawrence Erlbaum.

Campbell, S. (1998). Translation into the second language. New York: Longman.

deFreitas, E. (2008). Enhancing identity through narrative: Interrupting the procedural discourse in mathematics in classrooms. In T. Brown (Ed.), The psychology of mathematics education: A psychoanalytic displacement (pp. 139-155). Rotterdam: Sense Publishing.

De Groot, M. B. A., \& Hoeks, J. C. J. (1995). The development of bilingual memory: Evidence from word translation by trilinguals. Language Learning, 45, 683-724.

ETS. (2005). TOEFL actual tests: 7 full-length paper-based exams administered in the past by ETS. Cambridge: Cambridge University Press.

Francis, S. W., \& Gallardm S. L. K. (2005). Concept mediation in trilingual translation: Evidence from response time and repetition priming patterns. Psychonomic Bulletin \& Review, 12, 1082-1088.

Francis, S. W., Tokowicz, N., \& Kroll, J. F. (2014). The consequences of language proficiency and difficulty of lexical access for translation performance and priming. Mem Cogn, 42, 27-40.

Gardner, H. (1990). Frames of mind: The theory of multiple intelligences. San Francisco: Basic.

Goleman, D. (1995). Emotional intelligence. New York: Bantam.

Giuseppe, M. (1981). On the need of psycholinguistic research on translation. International Journal of Psycholinguistics, 8(2), 79-107.

Hatim, B., \& Mason, I. (1997). The translator as communicator. London: Routledge.

Kaplan, D. (2009). Structural equation modeling. London: Sage Publication.

Kroll, F. J., \& Curley, J. (1988). Lexical memory in novice bilinguals: The role of concepts in retrieving second language words. In M. M. Gruneberg, P. E. Morris, \& R. N. Skykes (Eds.), Practical aspects of memory: Current research and issues: Vol. 2: Clinical and educational implications (pp. 389-395). Chichester: John Wiley \& Sons.

Kroll, F. J., \& Stewart, E. (1994). Category interference in translation and picture naming: Evidence for asymmetric connection between bilingual memory representations. Journal of Memory and Language, 33, 149-174.

Labov, W. (1997). Some further steps in narrative analysis. The Journal of Narrative and Life History, 7, 395-415. 
Li, B., Urban, S, L., Appling, D. S., \& Riedl, M. O. (2012). Crowdsourcing narrative intelligence. Advances in Cognitive systems, 1, 1-18.

Linacre, J. M. (2009). WINSTEPS Rasch program. Version 3.63.0.

Malakoff, M. E. (1992). Translation ability: A natural bilingual and metalinguistic skill. In R. L. Harris (Ed.), Cognitive processing in bilinguals (pp. 515-529). Amsterdam: Elsevier Science.

Manfredi, M. (2008). Translating text and context: Translation studies and systemic functional linguistics, Vol. 1: Translation theory (Quaderni del CeSLiC: Functional grammar studies for non-native speakers of English). Bologna: DUPress.

Mateas, M. (1999). An oz-centric review of interactive drama and believable agents. In M.Wooldridge \& M. Veloso (Eds.), AI today: Recent trends and developments (pp. 297-328). Berlin, New York: Springer.

Mohammadi, M., \& Mousalou, R. (2012). Emotional intelligence, linguistic intelligence, and their relevance to speaking anxiety of EFL learners. Journal of Academic and Applied Studies, 2(6), 11-22

Neubert, A. (2000). Competence in language, in languages, and in translation. In C. Schaffner, \& B. Adab (Eds.), Developing translation competence (pp. 3-18). Amsterdam \& Philadelphia: Benjamins.

Pishghadam, R. (2007). The influence of emotional and verbal intelligences on second language learning. Unpublished doctoral dissertation, Allame Tabatabai University, Tehran, Iran.

Pishghadam, R. (2009). Emotional and verbal intelligences in language learning. Iranian Journal of Language Studies, 3, 43-64.

Pishghadam, R., Baghaei, P., Shams, M. A., \& Shamsaee, S. (2011). Construction and validation of a narrative intelligence scale with the Rasch rating scale model. The International Journal of Educational and Psychological Assessment, 8(1), 75-90.

Pishghadam, R., \& Motakef, R. (2012). Narrative intelligence and learning languages. International Journal of Language Teaching and Research, 1(1), 13-20.

Pishghadam, R., \& Shams, M. A. (2013). A new look into the construct validity of IELTS speaking module. The Journal of Language Teaching Skills, 5(1), 71-90.

Potter, C. M., So, K. F., Eckardt, B. V., \& Feldman, L. B. (1984). Lexical and conceptual representation in beginning and more proficient bilinguals. Journal of Verbal Learning and Verbal Behaviour, 23, 23-38.

Qian, D. D. (1999). Assessing the roles of depth and breadth of vocabulary knowledge in reading comprehension. Canadian Modern Language Review, 56, 282-308.

Randall, W. L. (1999). Narrative intelligence and the novelty of our lives. Journal of Aging Studies, 13(1), 11-28.

Read, J. (1993). The development of a new measure of L2 vocabulary knowledge. Language Testing, 10, 355-377.

Sechrest, L., Fay, T. L., \& Zaidi, H. S. M. (1972). Problems of translation in cross cultural research. Journal of Cross-Cultural Psychology, 3(9), 41-56.

Shangarffam, N., \& Abolsaba, A. (2009). The relationship between emotional intelligence and the quality of translation. Journal of Teaching English as a Foreign Language and Literature, Islamic Azad University, North Tehran Branch, 1(2), 103-114.

Silva, A. M. (2008). Development of the WAIS-III: A brief overview, history, and description. Graduate Journal of Counselling Psychology, 1, 117-135.

Snodgrass, J. G. (1993). Translating vs. picture naming: Similarities and differences. In R. Schreuder, \& B. Weltens (Eds.), The bilingual lexicon (pp. 83-114). Amsterdam: John Benjamins.

Somers, R. M., \& Gibson, D. G. (1994). Reclaiming the epistemological 'Other': Narrative and the social constitution of identity. In C. Calhoun (Ed.), Social theory and the politics of identity (pp. 37-99). Oxford UK \& Cambridge USA: Blackwell.

Uzawa, K. (1996). Second language learners’ processes of L1 writing, L2 writing, and translation from L1 into L2. Journal of Second Language Writing, 5(3), 271-294.

Waddington, C. (2001). Different methods of evaluating student translation: The question of validity. Meta: Translator's Journal, 46(2), 311-325. 
Wechsler, D. (1981). Wechsler adult intelligence scale revised. San Antonio, TX: Psychological Corporation.

Wills, W. (1998). Decision making in translation. In M. Baker (Ed.), Routledge encyclopedia of translation studies (pp. 57-60). London/New York: Routledge.

Zavalaa, D. F. (2012). The suitable kind of multiple intelligence for translation students (Unpublished B.A. thesis, Universidad Autonoma del Carmen, Mexico). Retrieved from http://www.scribd.com/doc/111069883/ Multiple-IntelligencesApplied to- Translation-Students-Thesis. 


\section{Appendix}
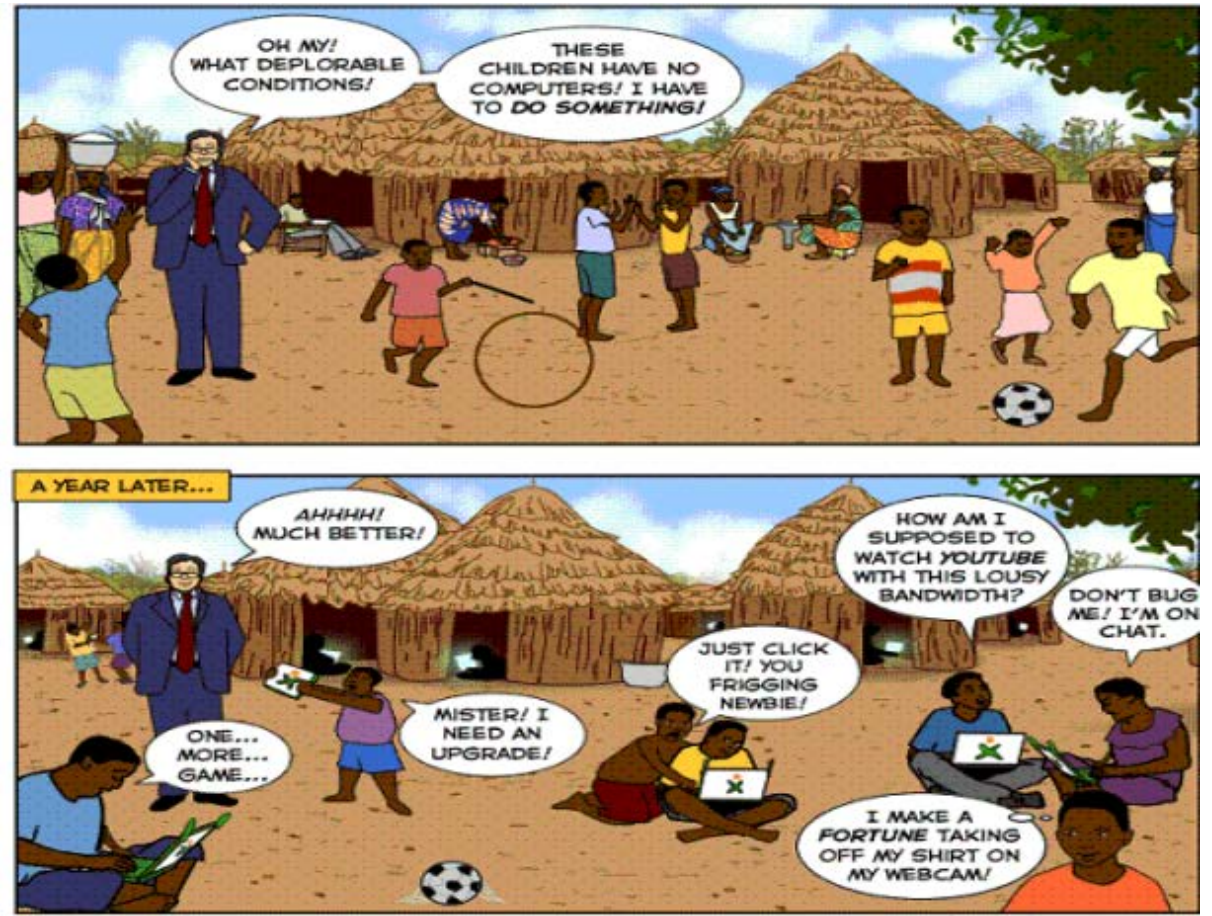

A sample of a picture story

(Retrieved from: www.joyoftech.com) 